\title{
Pengaruh Online Consumer Review dan Rating terhadap Minat Beli Produk Kesehatan pada E-Marketplace Shopee Selama Masa Pandemi COVID-19
}

\author{
Izzatul Islami Harli \\ IPB University, Dramaga, Bogor 16680 \\ Ali Mutasowifin \\ IPB University, Dramaga, Bogor 16680 \\ M. Syaefudin Andrianto \\ IPB University, Dramaga, Bogor 16680 \\ Email: alimu@apps.ipb.ac.id
}

\begin{abstract}
Abstrak
Pandemi COVID-19 mendorong peningkatan penjualan produk-produk kesehatan seperti masker, handsanitizer, obat-obatan dan lain-lain. Sebagai pemimpin pasar e-marketplace yang sedang berkembang di Indonesia, Shopee menyediakan fitur online consumer review dan rating pada platformnya. Penelitian ini bertujuan untuk menganalisis pengaruh online consumer review dan rating terhadap minat beli produk kesehatan pada e-marketplace Shopee selama masa pandemi COVID-19 di Jabodetabek. Penarikan sampel dilakukan dengan teknik purposive sampling. Metode yang digunakan dalam penelitian ini adalah analisis deskriptif dan SEM-PLS, dengan responden sebanyak 191 orang. Hasil analisis menunjukkan variabel online consumer review dan rating berpengaruh positif dan signifikan terhadap minat beli produk kesehatan dengan variabel rating memiliki pengaruh lebih dominan.
\end{abstract}

Kata Kunci: minat beli, online consumer review, produk kesehatan, rating, shopee

\section{Pendahuluan}

Pada Desember 2019, World Health Organization (WHO) melaporkan telah terjadi kasus pneumonia di Kota Wuhan, Provinsi Hubei, Tiongkok (Zhu et al. 2020). Pandemi COVID-19 sendiri menyebar di Indonesia sejak bulan Maret 2020. Berbagai negara menerapkan kebijakan lockdown atau di Indonesia disebut dengan pelbagai istilah, seperti Pembatasan Sosial Berskala Besar (PSBB) dan Pemberlakuan Pembatasan Kegiatan Masyarakat (PPKM) guna mengurangi penyebaran virus COVID-19. Kebijakan ini berdampak pada pola hidup masyarakat yang semula banyak menghabiskan waktu di luar rumah, sekarang menjadi lebih sering menghabiskan waktu di dalam rumah, mulai dari sekolah, bekerja, hingga berbelanja. Pengguna internet di Indonesia yang terus bertambah menjadi pasar yang sangat menjanjikan bagi para pelaku e-commerce, sehingga banyak e-commerce dan marketplace yang bermunculan seperti Matahari Mall, Shopee, Bukalapak, Lazada, Blibli, Tokopedia, dan lain-lain (Mulyati dan Gesitera 2020). 
INOBIS: Jurnal Inovasi Bisnis dan Manajemen Indonesia

Volume 04, Nomor 04, September 2021

Izzatul Islami Harli, Ali Mutasowifin, M. Syaefudin Andrianto

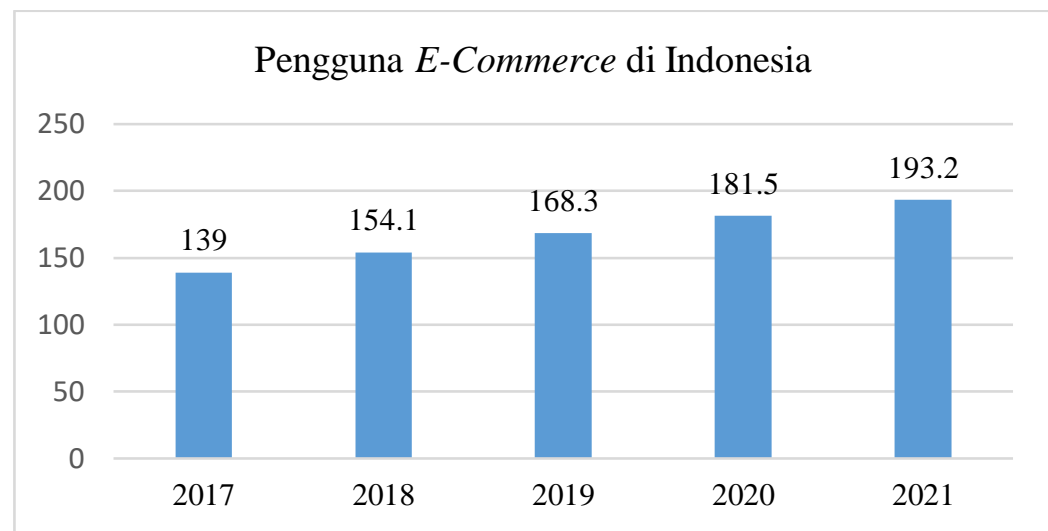

Gambar 1. Pengguna E-Commerce di Indonesia

Sumber : Statista 2019 (data diolah)

Berdasarkan Gambar 1, terlihat bahwa pengguna e-commerce pada tahun 2018 sebesar 154,1 juta pengguna, kemudian pada tahun 2019 meningkat menjadi 168,3 juta dan tahun 2021 diproyeksikan mencapai 193,2 juta pengguna. Hal ini menunjukkan bahwa jumlah pengguna e-commerce di Indonesia meningkat setiap tahunnya. Bachdar (2018) menjelaskan hasil riset Snapchart terkait perilaku belanja e-commerce di Indonesia menunjukkan bahwa daerah pembelanja e-commerce tertinggi di Indonesia adalah DKI Jakarta $(22 \%)$ dan Jawa Barat (21\%) di mana daerah tersebut merupakan kawasan metropolitan, khususnya daerah Jabodetabek.

Tabel 1. Urutan E-Marketplace Berdasarkan Ranking Aplikasi 2020

\begin{tabular}{|l|c|c|c|c|c|c|c|c|}
\hline \multirow{2}{*}{ E-Marketplace } & \multicolumn{4}{|c|}{ Ranking Appstore } & \multicolumn{4}{c|}{ Ranking Playstore } \\
\cline { 2 - 9 } & Q1 & Q2 & Q3 & Q4 & Q1 & Q2 & Q3 & Q4 \\
\hline Shopee & $\# 1$ & $\# 1$ & $\# 1$ & $\# 1$ & $\# 1$ & $\# 1$ & $\# 1$ & $\# 1$ \\
\hline Tokopedia & $\# 2$ & $\# 2$ & $\# 2$ & $\# 2$ & $\# 3$ & $\# 3$ & $\# 4$ & $\# 4$ \\
\hline Lazada & $\# 3$ & $\# 3$ & $\# 3$ & $\# 3$ & $\# 2$ & $\# 2$ & $\# 3$ & $\# 3$ \\
\hline Bukalapak & $\# 4$ & $\# 4$ & $\# 4$ & $\# 7$ & $\# 4$ & $\# 4$ & $\# 5$ & $\# 7$ \\
\hline
\end{tabular}

Sumber : iPrice, 2020 (data diolah)

Berdasarkan Tabel 1, Shopee secara konsisten menduduki peringkat pertama di platform iOS dan Android. Sejak kuartal 1 tahun 2020, Shopee selalu menjadi nomor 1 di Playstore maupun Appstore. Dalam laman katadata.co.id (2020), transaksi Shopee pada kuartal II tahun 2020 atau saat pandemi COVID-19 sebesar 160 juta transaksi atau meningkat 130\% secara tahunan dengan rata-rata transaksi per hari mencapai 2,8 juta. Selain itu, Shopee juga menduduki peringkat pertama e-commerce dengan jumlah pengunjung situs terbanyak di Indonesia pada kuartal IV 2020 yaitu sebesar 129,3 juta pengunjung per bulan. Hal ini dapat dilihat pada Gambar 2. 
INOBIS: Jurnal Inovasi Bisnis dan Manajemen Indonesia

Volume 04, Nomor 04, September 2021

Izzatul Islami Harli, Ali Mutasowifin, M. Syaefudin Andrianto

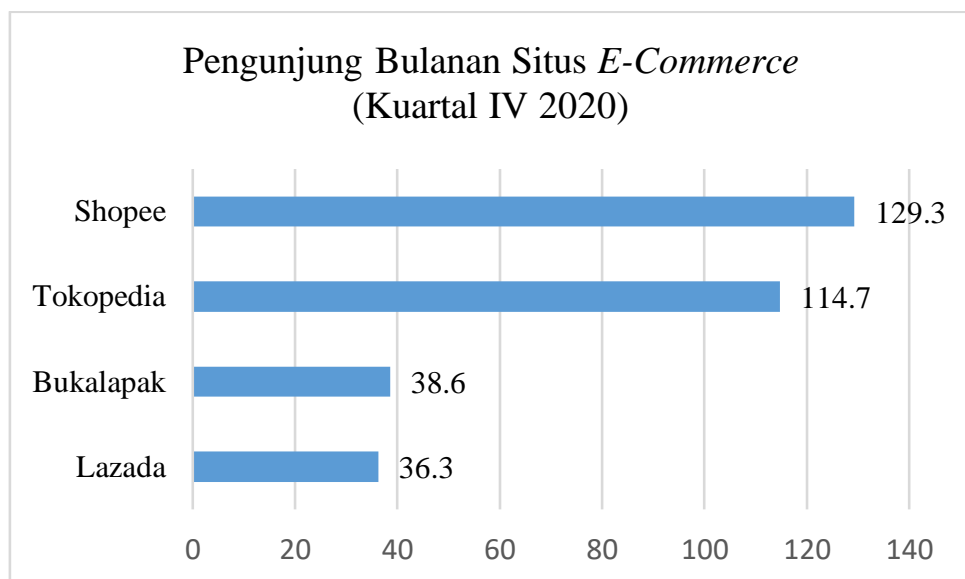

Gambar 2. Pengunjung Bulanan Situs E-Commerce (Kuartal IV 2020)

Sumber : iPrice, 2021 (data diolah)

Kesehatan menjadi hal yang penting saat masa pandemi COVID-19. Oleh karena itu produk-produk kesehatan seperti masker, handsanitizer, suplemen, obat-obatan, dan lainnya menjadi produk yang paling dicari oleh konsumen saat ini. Dalam laporan PricewaterhouseCoopers (PWC), pengeluaran prioritas konsumen Indonesia setelah adanya pandemi COVID-19 ada pada produk kesehatan yaitu sebanyak 77\%. Data tersebut dapat dilihat pada Gambar 3.

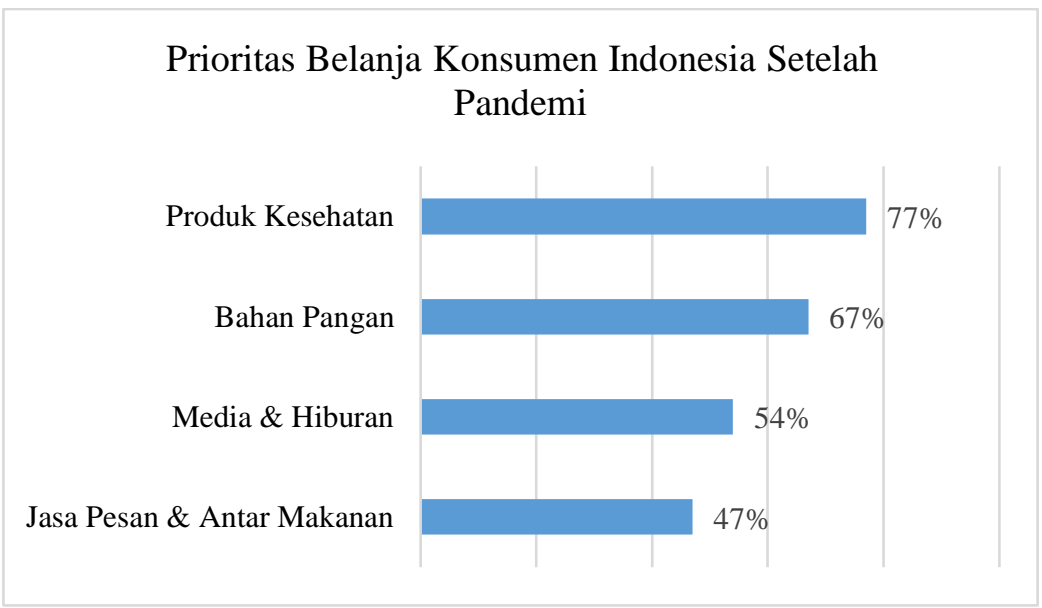

Gambar 3. Prioritas Belanja Konsumen Indonesia Setelah Pandemi

Ketika berbelanja online, konsumen sering merasa kesulitan untuk menilai apakah produk tersebut sesuai dengan apa yang diinginkaan atau tidak. Oleh karena itu konsumen berusaha memperoleh informasi melalui review dan rating yang tersedia di berbagai platform online termasuk e-marketplace yang biasa disebut dengan online consumer review (OCR). Dengan berkembangnya popularitas internet, online consumer review telah menjadi sumber informasi penting bagi konsumen yang ingin mengetahui kualitas suatu produk (Zhu dan Zhang 2010). Ulasan konsumen online cenderung lebih relevan bagi konsumen dibanding informasi yang disediakan oleh penjual (Chen dan Xie 2008). Selain OCR, rating juga juga menjadi sumber informasi bagi konsumen ketika berbelanja. Rating merupakan bagian dari review yang menggunakan bentuk simbol bintang untuk menampilkan pendapat dari pelanggan (Arbaini 2020). 
Adanya fitur review dan rating memberikan dampak yang baik bagi konsumen ataupun penjual. Konsumen dapat memperoleh informasi yang lebih detail terkait produk yang akan dibeli dan penjual memperoleh feedback yang bermanfaat untuk keperluan evaluasi toko kedepannya. Selain itu, dengan adanya online consumer review dan rating dapat menimbulkan minat beli yang lebih kuat bagi pelanggan. Ling et al. (2010) mengemukakan bahwa purchase intention (minat beli) online adalah sebuah situasi dimana konsumen bersedia dan berniat untuk terlibat dalam sebuah transaksi pembelian online.

Oleh karena pandemi COVID-19 masih menyebar di Indonesia, masyarakat membatasi aktivitas di luar rumah. Perilaku belanja konsumen mulai menyesuaikan agar pandemi ini tidak menghambat kegiatan perbelanjaan. Produk-produk kesehatan seperti masker, handsanitizer, suplemen, obat-obatan dan lainnya menjadi hal yang paling dicari konsumen pada masa pandemi COVID-19. Penelitian ini berfokus pada Shopee sebagai e-marketplace yang tengah memimpin saat ini sehingga dapat menjadi cerminan bagi e-marketplace lainnya terkait efektivitas fitur review dan rating dalam meningkatkan minat beli konsumen. Berdasarkan hal tersebut, penelitian ini bertujuan menelaah pengaruh online consumer review dan rating terhadap minat beli produk kesehatan pada $e$-marketplace Shopee selama pandemi COVID-19 di Jabodetabek.

Berdasarkan latar belakang yang telah dipaparkan, maka rumusan masalah dalam penelitian ini adalah sebagai berikut:

1. Bagaimana karakteristik responden pengguna E-marketplace shopee selama masa pandemi COVID-19 di Jabodetabek?

2. Bagaimana pengaruh online consumer review terhadap minat beli produk kesehatan pada E-marketplace Shopee selama masa pandemi COVID-19 di Jabodetabek?

3. Bagaimana pengaruh rating terhadap minat beli produk kesehatan pada E-marketplace Shopee selama masa pandemi COVID-19 di Jabodetabek?

\section{Landasan Teori dan Pengembangan Hipotesis}

\section{E-Marketplace}

Menurut Husnurrosyidah (2019) electronic marketplace (e-marketplace) merupakan suatu pasar virtual dimana pasar tersebut menjadi tempat bertemunya penjual serta pembeli untuk melakukan transaksi. Dalam marketplace, konsumen dan pelaku usaha melakukan proses transaksi dengan melakukan pertukaran barang maupun jasa untuk menghasilkan uang (Ardianti dan Widiartanto 2019). Salah satu hal yang membedakan marketplace dengan model bisnis online lainnya yaitu marketplace terdiri dari banyak penjual yang menjual produknya di pasar online

\section{Online Consumer Review}

Menurut Almana dan Mirza (2013) online consumer review merupakan analisis serta komentar yang dihasilkan dan diposting oleh konsumen akhir produk yang sebelumnya telah membeli dan menggunakan produk tersebut. Sedangkan menurut Park et al. (2006) online consumer review adalah informasi baru yang didalamnya terdapat pengalaman, evaluasi, dan pendapat tentang suatu produk dari perspektif konsumen. Menurut Chen et al. (2015) dimensi dari online consumer review ada 3, yaitu :

\section{Motivation}

Motivasi menggambarkan unsur-unsur yang menyebabkan konsumen mencari informasi secara online melalui komunikasi eWOM pada ulasan online. Menurut Pakdel (2013), motivasi merupakan hal yang membangkitkan energi dan mengarahkannya ke perilaku yang stabil atau bisa disebut sebagai tingkat dan perilaku ketegangan yang terjadi 
dalam status perilaku seseorang. Analisis data menunjukkan bahwa dimensi motivation memiliki 3 subdimensi yaitu search, benefit, dan support.

2. Source

Dimensi source merujuk kepada asal dari suatu komunikasi online, dalam hal ini merupakan online review. Dimensi source menggambarkan dampak yang ditimbulkan oleh elemen-elemen tertentu dari suatu ulasan online terhadap konsumen. Dimensi source memiliki 3 subdimensi, yaitu influence, trust, dan characteristic.

3. Content

Dimensi content mengidentifikasi pentingnya konten eWOM pada ulasan online. Konten yang jelas dan menarik dapat mendorong konsumen lainnya untuk membeli produk tersebut. Analisis data menunjukkan terdapat dua subdimensi pada content, yaitu teknologi dan gambar sebagai aspek yang mempengaruhi proses pengambilan keputusan pembelian konsumen.

\section{Rating}

Menurut Munte et al. (2020), online consumer rating merupakan penilaian dari konsumen terkait preferensi suatu produk terhadap pengalaman konsumen yang mengacu pada keadaan psikologis dan emosional yang di rasakan ketika berinteraksi dengan produk. Sedangkan menurut Lackermair et al. (2013), online consumer rating digunakan untuk merepresentasikan pendapat pelanggan pada skala tertentu. Menurut Lee dan Shin (2014) rating terdiri dari 3 dimensi, yaitu :

1. Kredibel (Credible), terdiri dari :

a. Dapat dipercaya (Trustworthy)

b. Jujur (Honest)

2. Keahlian (Expert), terdiri dari :

a) Professional (Professional)

b) Berguna (Useful)

3. Menyenangkan (Likable), terdiri dari :

a) Menyenangkan (Likable)

b) Menarik (Interesting)

c) Kemungkinan untuk membeli dari situs web tersebut (Likely to buy from this website)

\section{Minat Beli}

Schiffman dan Kanuk (2007) mengemukakan bahwa minat beli merupakan timbulnya aktivitas psikis berupa rangsangan dan pikiran terhadap suatu produk baik barang ataupun jasa yang diinginkan. Sedangkan menurut Saidani dan Arifin (2012), minat beli merupakan perilaku kecenderungan konsumen untuk bertindak sebelum keputusan pembelian terhadap suatu produk ditetapkan. Menurut Ferdinand (2002) dalam (Saidani dan Arifin 2012), minat beli terbagi kepada beberapa indikator, yaitu:

1. Minat transaksional, yaitu kecenderungan konsumen untuk melakukan pembelian terhadap produk yang diinginkan.

2. Minat referensial, yaitu kecenderungan konsumen untuk mereferensikan produk yang telah dibeli agar konsumen lain juga membeli produk yang sama.

3. Minat preferensial, yaitu perilaku konsumen yang menjadikan produk yang telah dikonsumsinya sebagai pilihan utama. Produk ini hanya dapat diganti jika terjadi sesuatu pada produk preferensinya.

4. Minat eksploratif, yaitu perilaku seseorang yang selalu ingin mencari tahu terkait informasi produk yang diminati melalui berbagai sumber yang mendukung sifat-sifat positif dari produk tersebut. 


\section{Pengembangan Hipotesis}

\section{Pengaruh Online Consumer Review dan Rating terhadap Minat Beli}

Review dan rating berkualitas tinggi yang terdiri dari informasi spesifik terkait produk akan menyebabkan minat pembelian yang lebih kuat (Munte et al. 2020). Penelitian Farki (2016) menunjukkan bahwa variabel review dan rating berpengaruh positif dan signifikan terhadap minat beli. Berdasarkan hal tersebut, peneliti merumuskan hipotesis penelitian sebagai berikut :

$\boldsymbol{H}_{1}$ : Online consumer review berpengaruh positif dan signifikan terhadap minat beli $\boldsymbol{H}_{2}:$ Rating berpengaruh positif dan signifikan terhadap minat beli

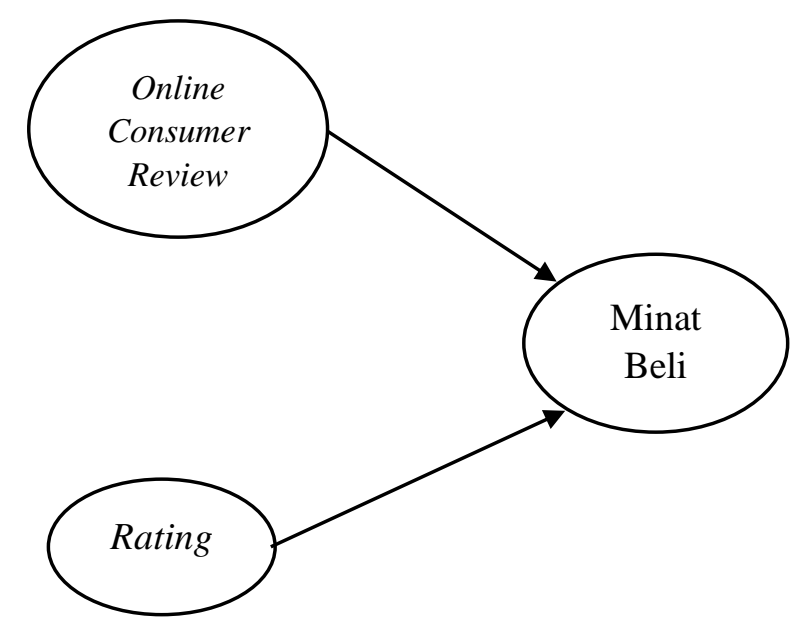

Gambar 4. Model Penelitian

\section{Metode Penelitian}

Penelitian ini dilaksanakan secara online dengan menyebarkan kuesioner kepada responden pengguna e-marketplace Shopee selama pandemi COVID-19 yang berdomisili di Jabodetabek dan pernah berbelanja produk kesehatan (masker, handsanitizer, suplemen, obatobatan, dan lain-lain). Penelitian ini dilaksanakan pada bulan Mei 2021. Sumber data pada penelitian ini menggunakan data primer dan data sekunder. Data primer diperoleh melalui penyebaran kuesioner kepada responden yaitu pengguna E-marketplace Shopee yang berdomisili di Jabodetabek dan pernah berbelanja produk kesehatan (masker, handsanitizer, suplemen, obat-obatan, dan lain-lain) selama pandemi COVID-19. Sedangkan untuk data sekunder diperoleh dari studi literatur, buku, jurnal, skripsi, dan website.

Penarikan sampel pada penelitian ini menggunakan metode non probability sampling dengan teknik purposive sampling. Teknik analisis yang digunakan pada penelitian ini adalah analisis deskriptif dan analisis SEM-PLS. Metode pengambilan sampel pada penelitian ini menggunakan rumus Hair et al. Menurut Hair et al. (2010) jumlah sampel setidaknya 5 kali dari total indikator yang akan dianalisis. Pada penelitian ini terdapat sebanyak 32 indikator yang akan dianalisis, maka jumlah sampel yang akan diteliti adalah 5 dikali 32 yaitu sebanyak 160 responden. Jumlah responden yang dianalisis dalam penelitian ini adalah sebanyak 191 responden. 


\section{Definisi Operasional Variabel}

Pada penelitian ini terdapat tiga variabel yang akan diuji. Definisi operasional variabel yang digunakan dalam penelitian ini tersedia dalam Tabel 2.

Tabel 2. Definisi Operasional Variabel

\begin{tabular}{|c|c|c|c|}
\hline No. & Variabel & Definisi Operasional & Dimensi \\
\hline \multicolumn{4}{|c|}{ Variabel Dependen } \\
\hline 1. & Minat Beli & $\begin{array}{l}\text { Timbulnya aktivitas psikis berupa } \\
\text { rangsangan dan pikiran terhadap suatu } \\
\text { produk baik barang ataupun jasa yang } \\
\text { diinginkan (Schiffman dan Kanuk } \\
\text { 2007) }\end{array}$ & $\begin{array}{ll}\text { 1. } & \text { Minat } \\
\text { transaksional } \\
\text { 2. } \\
\text { 3. } & \text { Minat referensial } \\
\text { 4. } & \text { Minat eksploratif } \\
& \text { (Ferdinand 2002) }\end{array}$ \\
\hline \multicolumn{4}{|c|}{ Variabel Independen } \\
\hline 1. & $\begin{array}{l}\text { Online } \\
\text { Consumer } \\
\text { Review }\end{array}$ & $\begin{array}{l}\text { Analisis serta komentar yang dihasilkan } \\
\text { dan diposting oleh konsumen akhir } \\
\text { produk yang sebelumnya telah membeli } \\
\text { dan menggunakan produk tersebut } \\
\text { (Almana dan Mirza 2013) }\end{array}$ & $\begin{array}{ll}\text { 1. } & \text { Motivation } \\
\text { 2. } & \text { Source } \\
\text { 3. } & \text { Content } \\
\text { (Chen et al. 2015) }\end{array}$ \\
\hline 2. & Rating & 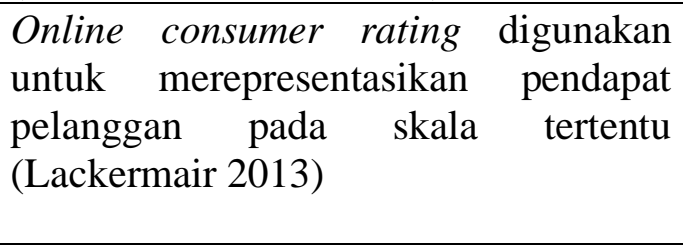 & $\begin{array}{l}\text { 1. Credibel } \\
\text { 2. Expert } \\
\text { 3. Likable } \\
\text { (Lee dan Shin } \\
\text { 2014) }\end{array}$ \\
\hline
\end{tabular}

\section{Pembahasan}

\section{Karakteristik Responden}

Karakteristik responden dalam penelitian ini dibedakan berdasarkan jenis kelamin, usia, status pernikahan, domisili, pekerjaan, pendidikan terakhir, pemasukan per bulan, dan frekuensi berbelanja produk kesehatan dalam 1 bulan di Shopee. Hasil perolehan data mengenai karakteristik responden tersedia dalam Tabel 3.

Tabel 3. Karakteristik Responden

\begin{tabular}{|l|l|l|}
\hline Kategori & Keterangan & Persentase \\
\hline \multirow{3}{*}{ Uenis Kelamin } & Laki-laki & 16.6 \\
\cline { 2 - 3 } & Perempuan & 83.4 \\
\hline \multirow{5}{*}{ Status Pernikahan } & $<25$ tahun & 81.3 \\
\cline { 2 - 3 } & $25-34$ tahun & 8.8 \\
\cline { 2 - 3 } & $35-45$ tahun & 9.3 \\
& $>45$ tahun & 0.6 \\
\hline Domisili & Belum Menikah & 81.3 \\
\cline { 2 - 3 } & Sudah Menikah & 18.7 \\
\hline
\end{tabular}


INOBIS: Jurnal Inovasi Bisnis dan Manajemen Indonesia

Volume 04, Nomor 04, September 2021

Izzatul Islami Harli, Ali Mutasowifin, M. Syaefudin Andrianto

\begin{tabular}{|c|c|c|}
\hline & Bogor & 40.9 \\
\hline & Depok & 7.3 \\
\hline & Tangerang & 14.5 \\
\hline & Bekasi & 12.4 \\
\hline \multirow[t]{6}{*}{ Pekerjaan } & Pelajar/Mahasiswa & 73.1 \\
\hline & Pegawai Swasta & 7.8 \\
\hline & Ibu Rumah Tangga & 8.3 \\
\hline & Pegawai Negeri & 3.1 \\
\hline & Wiraswasta & 2.6 \\
\hline & Lainnya & 5.1 \\
\hline \multirow{5}{*}{ Pendidikan Terakhir } & SMA/Sederajat & 55.9 \\
\hline & Diploma & 5.7 \\
\hline & Sarjana (S1) & 34.7 \\
\hline & S2/S3 & 2.6 \\
\hline & Lainnya & 1.1 \\
\hline \multirow[t]{5}{*}{ Pemasukan (Rp/bulan) } & $<\mathrm{Rp} 2.500 .000$ & 68.4 \\
\hline & $\operatorname{Rp} 2.500 .000-\operatorname{Rp} 5.000 .000$ & 18.1 \\
\hline & $\operatorname{Rp} 5.000 .001-\operatorname{Rp} 7.500 .000$ & 5.7 \\
\hline & $\mathrm{Rp} 7.500 .001-\mathrm{Rp} 10.000 .000$ & 2.1 \\
\hline & $>\mathrm{Rp} 10.000 .000$ & 5.7 \\
\hline \multirow{4}{*}{$\begin{array}{l}\text { Frekuensi berbelanja } \\
\text { produk kesehatan dalam } \\
1 \text { bulan di Shopee }\end{array}$} & $1-3$ kali & 88.6 \\
\hline & $4-6$ kali & 9.3 \\
\hline & $7-10$ kali & - \\
\hline & $>10$ kali & 2.1 \\
\hline
\end{tabular}

Sumber : Data diolah (2021)

\section{Tanggapan Pengguna Shopee di Jabodetabek terhadap Online Consumer Review}

Hasil analisis deskriptif persepsi pengguna Shopee di Jabodetabek terhadap variabel online consumer review tersedia pada Tabel 4.

Tabel 4. Kriteria jawaban responden terkait variabel online consumer review

\begin{tabular}{|l|l|l|}
\hline Dimensi & Mean & Kriteria \\
\hline Motivation & 4.69 & Sangat setuju \\
\hline Source & 4.42 & Sangat setuju \\
\hline Content & 4.57 & Sangat setuju \\
\hline Online Consumer Review & $\mathbf{4 . 5 6}$ & Sangat setuju \\
\hline
\end{tabular}

Berdasarkan Tabel 4, responden dalam penelitian ini sangat setuju terhadap pernyataan terkait online consumer review yang diajukan dalam kuesioner. Hal ini menunjukkan bahwa para pengguna Shopee di Jabodetabek telah menggunakan fitur review di Shopee dengan baik ketika melakukan pembelian produk kesehatan. Dimensi yang memiliki nilai mean tertinggi adalah motivation yaitu sebesar 4.69 , hal ini menjelaskan bahwa pengguna Shopee di Jabodetabek mencari informasi secara online melalui review atau rating sebelum membeli produk kesehatan di Shopee. 


\section{Tanggapan Pengguna Shopee di Jabodetabek terhadap Rating}

Hasil analisis deskriptif persepsi pengguna Shopee di Jabodetabek terhadap variabel rating tersedia pada Tabel 5.

Tabel 5. Kriteria jawaban responden terkait variabel rating

\begin{tabular}{|l|l|l|}
\hline Dimensi & Mean & Kriteria \\
\hline Credible & 4.16 & Setuju \\
\hline Expert & 4.22 & Sangat setuju \\
\hline Likable & 4.48 & Sangat setuju \\
\hline Rating & $\mathbf{4 . 2 8}$ & Sangat Setuju \\
\hline
\end{tabular}

Berdasarkan Tabel 5, mayoritas responden menjawab sangat setuju terkait pertanyaan mengenai rating yang diajukan dalam kuesioner. Hal ini menunjukkan bahwa para pengguna Shopee di Jabodetabek percaya dan memanfaatkan fitur rating di Shopee dengan baik. Dimensi yang memiliki nilai mean tertinggi adalah likable yaitu sebesar 4.48 yang artinya pengguna Shopee di Jabodetabek merasa senang, tertarik, dan berminat dengan produk kesehatan yang memiliki rating tinggi di Shopee.

\section{Tanggapan Pengguna Shopee terhadap Minat Beli}

Hasil analisis deskriptif persepsi pengguna Shopee di Jabodetabek terhadap variabel minat beli dapat tersedia dalam Tabel 6 .

Tabel 6. Kriteria Jawaban responden terkait variabel minat beli

\begin{tabular}{|l|l|l|}
\hline Dimensi & Mean & Kriteria \\
\hline Minat transaksional & 4.41 & Sangat setuju \\
\hline Minat referensial & 4.21 & Sangat setuju \\
\hline Minat preferensial & 4.06 & Setuju \\
\hline Minat eksploratif & 4.40 & Sangat setuju \\
\hline Minat beli & $\mathbf{4 . 2 7}$ & Sangat setuju \\
\hline
\end{tabular}

Berdasarkan Tabel 6 dapat dilihat bahwa responden penelitian sangat setuju dengan pernyataan terkait minat beli yang diajukan dalam kuesioner. Mean terendah terdapat pada dimensi minat preferensial, hal ini menunjukkan pengguna Shopee di Jabodetabek belum sepenuhnya menjadikan Shopee sebagai pilihan utama ketika berbelanja produk kesehatan. Oleh karena itu Shopee harus berusaha untuk meningkatkan kualitas serta pelayanannya agar konsumen menjadikan Shopee pilihan utama dalam berbelanja produk kesehatan. Nilai mean tertinggi terdapat pada dimensi minat transaksional yaitu sebesar 4.41 yang artinya pengguna Shopee di Jabodetabek berminat untuk membeli produk kesehatan di Shopee setelah melihat review dan rating dari produk tersebut.

\section{Analisis Outer Model}

Analisis outer model dilakukan untuk mengetahui terkait uji validitas dan reliabilitas setiap indikator dengan variabel latennya. Menurut Chin (1998) dalam Ghozali (2012), suatu indikator dapat dianggap valid jika nilai loading factor $>0.5$ dan apabila belum memenuhi syarat akan dilakukan dropping satu persatu kemudian dilakukan run kembali. Setelah dilakukan estimasi, terdapat sepuluh indikator yang tidak memenuhi syarat yaitu indikator 
OC2, OC3, OM1, OM2, OM3, OS2, OS6, Y5, Y6, dan Y8. Indikator-indikator tersebut di dropping dari model penelitian dan didapatkan model baru yang dapat dilihat pada Gambar 5.

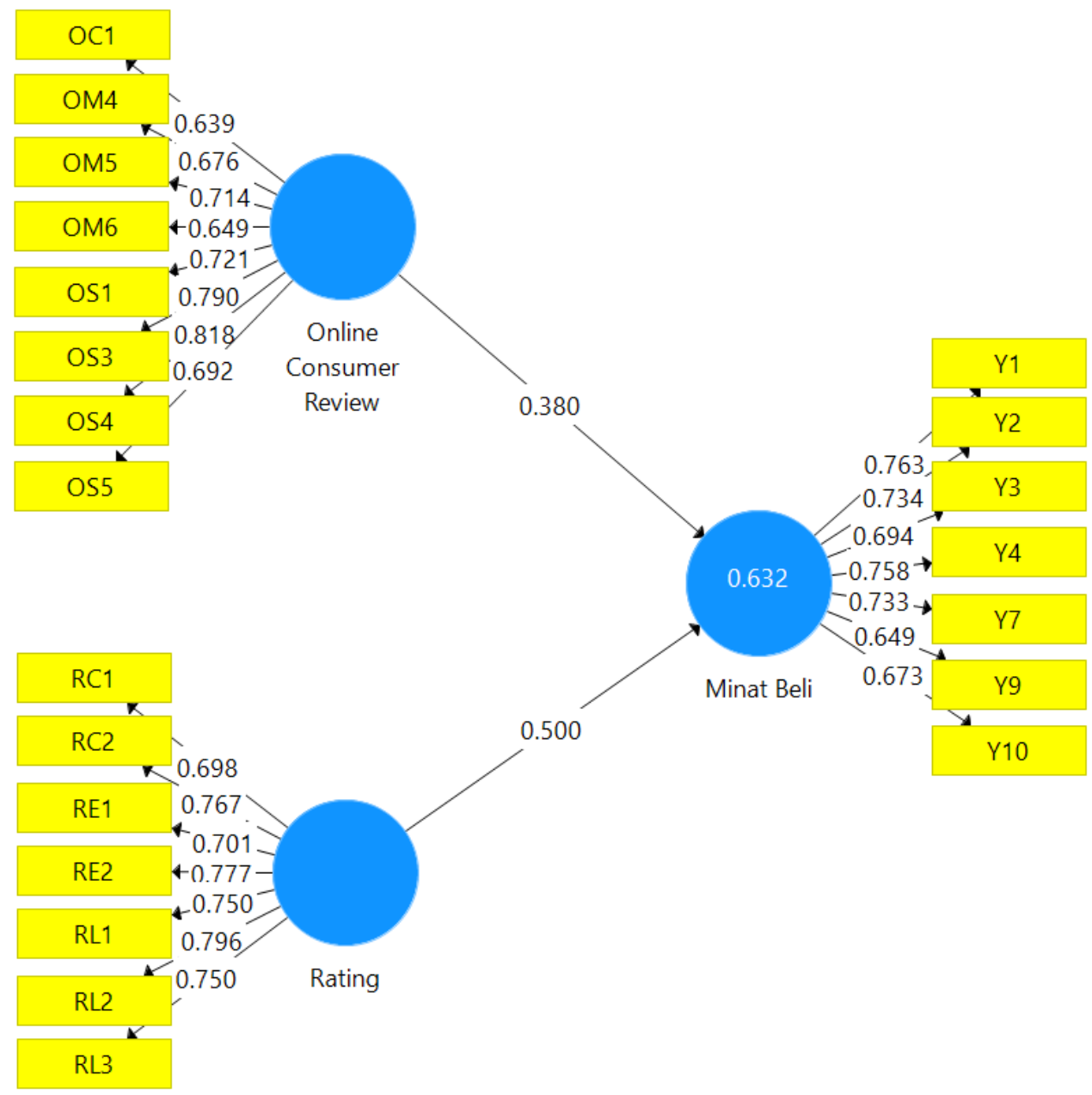

Gambar 5. Model Akhir Penelitian

Nilai pengukuran indikator tertinggi variabel online consumer review terdapat pada OS4 (Shopee memberikan kepuasan ketika bertransaksi dengan adanya fitur online review) dengan loading factor sebesar 0.818. Hal ini menggambarkan bahwa konsumen merasa puas ketika melakukan transaksi di Shopee karena adanya fitur online review. Fitur online review dapat membantu untuk mengetahui informasi produk kesehatan yang akan dibeli agar sesuai dengan ekspektasi konsumen.

Nilai pengukuran tertinggi pada variabel rating terdapat pada RL2 (tertarik dengan produk yang memiliki rating tinggi) dengan loading factor sebesar 0.796. Hal ini menggambarkan bahwa konsumen cenderung lebih tertarik dengan produk kesehatan yang memiliki rating tinggi dikarenakan semakin tinggi rating suatu produk, menggambarkan produk tersebut semakin bagus. Biasanya rating di e-marketplace direpresentasikan dengan simbol bintang satu sampai lima, dimana bintang satu menandakan bahwa kualitas dari produk ataupun layanan yang diberikan oleh suatu toko sangat buruk dan bintang lima menandakan bahwa kualitas produk dan layanan yang diberikan sangat baik.

Nilai pengukuran indikator tertinggi variabel minat beli terdapat pada Y1 (setelah membaca review tertarik untuk membeli) dengan loading factor sebesar 0.763 . Hal ini 
menggambarkan bahwa konsumen akan tertarik untuk membeli suatu produk kesehatan setelah melihat review-review terkait produk tersebut.

Selanjutnya, metode lain yang digunakan untuk melakukan uji validitas dan reliabilitas suatu konstruk adalah dengan melihat nilai AVE, cronbach's alfa, dan composite reliability. Suatu variabel dapat dikatakan telah memenuhi syarat valid dan reliabel jika nilai AVE > 0.5 (Hair et al. 2014), nilai cronbach's alfa >0.6 (Hair et al. 2010) serta nilai composite reliability $>0.7$ (Vinzi et al. 2010). Hasil perhitungan nilai AVE, cronbach's alfa, dan composite reliability dapat dilihat pada Tabel 7 .

Tabel 7. Hasil Perhitungan Nilai AVE, Cronbach's Alfa, dan Composite Reliability

\begin{tabular}{|l|l|l|l|}
\hline Variabel & AVE & Cronbach's Alfa & $\begin{array}{l}\text { Composite } \\
\text { Reliability }\end{array}$ \\
\hline $\begin{array}{l}\text { Online Consumer } \\
\text { Review }\end{array}$ & 0.511 & 0.863 & 0.892 \\
\hline Rating & 0.561 & 0.870 & 0.899 \\
\hline Minat Beli & 0.513 & 0.842 & 0.880 \\
\hline
\end{tabular}

Sumber : Data diolah (2021)

Berdasarkan Tabel 7, dapat dilihat bahwa semua variabel telah memenuhi syarat valid dan reliabel suatu konstruk. Tahap selanjutnya yaitu melakukan evaluasi nilai discriminant validity dengan melihat nilai cross loading. Suatu variabel dan indikator dapat dikatakan valid apabila korelasi suatu konstruk dengan variabelnya lebih besar daripada korelasi konstruk dengan dengan variabel lain. Hasil penelitian menunjukkan bahwa korelasi konstruk dengan variabelnya memiliki nilai lebih tinggi dibandingkan nilai konstruk lainnya. Hal ini menunjukkan bahwa seluruh indikator telah dapat menggambarkan variabel latennya dengan baik dibanding indikator lain.

\section{Analisis Inner Model}

Tahap selanjutnya adalah melakukan evaluasi struktural (inner model) dengan melihat nilai $r$-square dan nilai $t$-statistic pada estimasi koefisien jalur (path coefficients) melalui proses bootstrapping. Nilai $r$-square menjelaskan pengaruh dari variabel laten eksogen terhadap variabel laten endogen. Nilai $r$-square pada model akhir penelitian dapat dilihat pada Tabel 8.

Tabel 8. Nilai $R$ Square

\begin{tabular}{|l|l|}
\hline Variabel Laten & $R$ Square \\
\hline Minat Beli & 0.632 \\
\hline
\end{tabular}

Sumber : Data diolah (2021)

Tabel 8 menunjukkan bahwa variabel online consumer review dan rating dapat menjelaskan pengaruhnya terhadap minat beli sebesar $63.2 \%$ dimana sisanya dijelaskan oleh variabel lain yang tidak diteliti dalam penelitian ini. Selanjutnya adalah melakukan analisis path coefficients dengan melihat nilai $t$-statistic melalui proses bootstrapping. Pada proses ini, peneliti dapat melihat apakah hipotesis yang telah dibuat pada model awal penelitian diterima atau ditolak. Nilai t-statistic menunjukkan signifikansi bahwa model penelitian dapat digunakan untuk melihat hubungan antara variabel laten eksogen dan endogen. Sedangkan nilai original sample menjelaskan sifat hubungan antar variabel (positif atau negatif). Apabila nilai 
t-statistic > nilai t-tabel yaitu sebesar 1.96 (tingkat signifikansi 5\%), maka hipotesis dapat diterima. Nilai path coefficient dapat dilihat pada Tabel 9.

Tabel 9. Nilai Path Coefficients

\begin{tabular}{|l|l|l|l|l|}
\hline Jalur Pengaruh & $\begin{array}{l}\text { Original } \\
\text { Sample }\end{array}$ & T-statistic & P-Values & Hipotesis \\
\hline $\begin{array}{l}\text { OCR -> Minat } \\
\text { Beli }\end{array}$ & 0.380 & 6.115 & $\mathbf{0 . 0 0 0}$ & Diterima \\
\hline $\begin{array}{l}\text { Rating -> } \\
\text { Minat Beli }\end{array}$ & 0.500 & 8.075 & $\mathbf{0 . 0 0 0}$ & Diterima \\
\hline
\end{tabular}

Sumber : Data diolah (2021)

Berdasarkan hasil analisis bootstrapping pada Tabel 9 didapatkan kesimpulan sebagai berikut:

1. Pengaruh Online Consumer Review terhadap Minat Beli

Berdasarkan Tabel 9 dapat dijelaskan bahwa variabel online consumer review memiliki pengaruh yang positif dan signifikan terhadap minat beli produk kesehatan pada e-marketplace Shopee selama pandemi COVID-19 di Jabodetabek. Hal ini dilihat dari nilai original sample sebesar 0.380 dan nilai $t$-statistic sebesar 6.115 . Oleh karena nilai $t$-statistic $>1.96$ maka hipotesis 1 diterima. Online consumer review pada aplikasi Shopee dapat menimbulkan munculnya minat beli produk kesehatan. Hasil ini menjelaskan bahwa dengan adanya fitur review pada e-marketplace Shopee, konsumen dapat mengetahui informasi terkait produk kesehatan yang hendak dibeli sehingga konsumen merasa lebih puas dan menimbulkan keinginan untuk membeli yang lebih tinggi.

Hasil penelitian ini selaras dengan penelitian Farki (2016) yang menyatakan bahwa variabel review berpengaruh positif dan signifikan terhadap minat beli. Pada $e$ marketplace, review dapat sangat berpengaruh terhadap minat beli karena review berasal dari pengalaman langsung konsumen sebelumnya yang membeli produk tersebut. Review menjadi salah satu sumber utama konsumen ketika ingin memutuskan minat pembelian. Oleh karena itu perusahaan harus mempersilahkan konsumen untuk menuliskan review yang jujur dan apa adanya agar dapat menciptakan minat beli konsumen berikutnya.

2. Pengaruh Rating terhadap Minat Beli

Pada Tabel 9 dapat dilihat bahwa rating memiliki pengaruh positif dan signifikan terhadap minat beli produk kesehatan pada e-marketplace Shopee selama pandemi COVID-19 di Jabodetabek. Hal ini dikarenakan rating memiliki nilai original sample positif sebesar 0.500. Rating merupakan penilaian konsumen terhadap performa dari suatu produk atau toko online yang disajikan dalam bentuk simbol. Maka ketika rating semakin tinggi maka akan semakin mempengaruhi minat konsumen untuk membeli produk tersebut.

Hasil penelitian ini memiliki kesamaan dengan penelitian Farki (2016) yang menyatakan bahwa rating berpengaruh positif dan signifikan terhadap minat beli. Namun, berbeda dengan penelitian Farki 2016, dalam penelitian ini variabel rating memiliki pengaruh yang lebih besar terhadap minat beli produk kesehatan dibandingkan variabel review. Hal ini diduga karena ketika pembeli akan membeli suatu produk, maka hal yang pertama dilihat adalah rating. Rating mencerminkan bagus atau tidaknya kualitas atau performa suatu produk. Selain itu, ketika memberikan rating konsumen tidak harus memberikan review terhadap produk tersebut sehingga jumlah konsumen yang memberikan rating biasanya cenderung lebih banyak dibanding review. Semakin tinggi suatu rating menunjukkan bahwa kualitas dan performa suatu produk atau toko semakin baik, hal ini dapat membuat konsumen lebih tertarik untuk membeli. 


\section{Implikasi Manajerial}

Berdasarkan hasil yang didapat pada penelitian maka dapat direkomendasikan implikasi manajerial menggunakan blue ocean strategy menurut Kim dan Mauborgne (2005), yang terdiri dari empat kerangka kerja yaitu reduce (kurangi), eliminate (hapuskan), raise (tingkatkan), create (ciptakan).

1. Reduce (kurangi)

Fitur review di Shopee masih terdapat beberapa kekurangan diantaranya masih banyak ditemukan review yang tidak berkaitan dengan produk yang dibeli. Hal ini dapat mengganggu konsumen lain yang ingin melihat review sebenarnya dari produk tersebut dan menyebabkan konsumen tidak puas dengan review yang tersedia. Pihak Shopee dapat meminimalisir hal ini terjadi dengan melakukan pemfilteran terhadap review-review yang tidak berkaitan dengan produk yang dibeli sehingga didapatkan kolom review hanya menyediakan informasi yang berguna bagi pembeli. Berdasarkan hasil penelitian, variabel online consumer review yang memiliki nilai loading factor tertinggi terdapat pada indikator OS4 yaitu Shopee memberikan kepuasan ketika bertransaksi dengan adanya fitur online review. Oleh karena itu Shopee perlu menjaga kepuasan konsumennya ketika menggunakan fitur review.

2. Eliminate (hapuskan)

Pihak Shopee sebaiknya menghapus produk-produk kesehatan yang dapat menghasilkan review dan rating yang negatif bagi konsumen. Berdasarkan hasil penelitian, variabel rating yang memiliki loading factor tertinggi terdapat pada indikator RL2 yaitu konsumen tertarik kepada produk kesehatan yang memiliki rating tinggi. Dengan banyaknya konsumen yang memberikan review dan rating yang baik, hal tersebut dapat memengaruhi minat pembelian konsumen berikutnya terhadap produk tersebut.

3. Raise (tingkatkan)

Pada fitur review, pihak Shopee dan seller dapat membuat default template review yang detail untuk diisi oleh para pembeli sehingga review-review yang dihasilkan menjadi lebih detail dan spesifik. Pada aplikasi Shopee telah ada beberapa toko yang menyediakan template, namun belum semua toko menyediakan template review. Para seller dpaat menyediakan template review seperti bagaimana fitur, harga, serta bahan dari produk tersebut agar lebih memudahkan konsumen mendapatkan informasi yang lebih detail dari review.

Terkait produk kesehatan yang dijual di Shopee, penjual sebaiknya meningkatkan keamanan, kebersihan, serta pelayanan yang diberikan kepada konsumen. Penjual dapat meningkatkan keamanan terhadap produk dengan memastikan packaging yang digunakan aman hingga sampai ke tangan konsumen, sehingga mengurangi kemungkinan produk cacat ketika di perjalanan. Selain itu, penjual juga harus memastikan kehigienisan produk yang dijual serta tempat penyimpanannya. Penjual juga harus memastikan bahwa produk yang dijual tidak kadaluarsa dan sesuai dengan yang tercantum di deskripsi maupun gambar. Hal ini dilakukan agar konsumen tidak memberikan review dan rating negatif yang dapat mengurangi minat pembelian terhadap produk tersebut bagi konsumen berikutnya.

4. Create (ciptakan)

Agar review yang didapat oleh penjual lebih kredibel dan detail, pihak seller dapat menyediakan customer service sendiri untuk menanyakan bagaimana pendapat konsumen terkait produk yang telah dibeli. Ketika konsumen selesai berbelanja, customer service dapat menanyakan terkait apa saja pendapat konsumen setelah menggunakan produk 
INOBIS: Jurnal Inovasi Bisnis dan Manajemen Indonesia

Volume 04, Nomor 04, September 2021

Izzatul Islami Harli, Ali Mutasowifin, M. Syaefudin Andrianto

tersebut agar penjual dapat mengevaluasi produk dan pelayanan secara lebih detail sesuai dengan pendapat konsumen.

\section{Kesimpulan}

Karakteristik pengguna Shopee di Jabodetabek didominasi oleh perempuan dengan usia $<25$ tahun dan berstatus belum menikah. Mayoritas responden berdomisili di Bogor. Status pekerjaan didominasi oleh pelajar/mahasiswa dengan tingkat pendidikatan terakhir SMA/Sederajat. Pemasukan per bulan didominasi oleh pengguna dengan pemasukan $<\mathrm{Rp}$ 2.500.000. Dalam satu bulan pengguna Shopee melakukan pembelian produk kesehatan sebanyak $1-3$ kali dengan produk yang paling sering dibeli yaitu produk masker. Online consumer review berpengaruh positif dan signifikan terhadap minat beli produk kesehatan di Shopee selama pandemi COVID-19 karena memberikan kepuasan kepada konsumen ketika berbelanja. Rating berpengaruh positif dan signifikan terhadap minat beli produk kesehatan di Shopee selama pandemi COVID-19, rating yang tinggi akan semakin memengaruhi minat pembelian konsumen. Rating memiliki pengaruh lebih besar terhadap minat beli produk kesehatan di Shopee dibanding online consumer review.

\section{Daftar Pustaka}

Almana AM, Mirza AA. 2013. The impact of electronic word of mouth on consumers purchasing intention. J Theor Appl Inf Technol. 98(2):183-193.

Arbaini P. 2020. Pengaruh Consumer Online Rating Dan Review Terhadap Keputusan Pembelian Pada Pengguna Marketplace Tokopedia. J Bisnis dan Manaj. 7(1):25-33. doi:10.26905/jbm.v7i1.3897.

Ardianti AN, Widiartanto MA. 2019. Pengaruh Online Customer Review dan Online Customer Rating terhadap Keputusan Pembelian melalui Marketplace Shopee . J Ilmu Adm Bisnis., siap terbit.

Bachdar S. 2018. Generasi Millenial Masih Pembelanja Online Terbesar di Indonesia [Internet]. [diakses pada 2021 Maret 26]. Tersedia pada : Generasi Milenial Masih Pembelanja Online Terbesar di Indonesia (marketeers.com)

Chen CH, Nguyen B, Klaus P "Phil", Wu MS. 2015. Exploring Electronic Word-of-Mouth (eWOM) in The Consumer Purchase Decision-Making Process: The Case of Online Holidays - Evidence from United Kingdom (UK) Consumers. J Travel Tour Mark. 32(8):953-970. doi:10.1080/10548408.2014.956165.

Chen Y, Xie J. 2008. Online consumer review: Word-of-mouth as a new element of marketing communication mix. Manage Sci. 54(3):477-491. doi:10.1287/mnsc.1070.0810.

Farki A, Baihaqi I, Wibawa M. 2016. Pengaruh Online Customer Review dan Rating Terhadap Kepercayaan dan Minat Pembelian pada Online Marketplace di Indonesia. 5(2).

Ferdinand A. 2002. Pengembangan Minat Beli Merek Ekstensi. Semarang(ID): Badan Penerbit Universitas Diponegoro

Ghozali. 2012. Aplikasi Analisis Multivariate dengan Program SPSS. Semarang: Universitas Diponegoro

Hair JF, Black W, Babin B, Anderson R. 2010. Multivariate Data Analysis. United States of America (USA): Prentice Hall.

Husnurrosyidah H. 2019. E-Marketplace Umkm Menghadapi Revolusi Industri 4.0 Dalam Perspektif Islam. Equilib J Ekon Syariah. 7(2):224. doi:10.21043/equilibrium.v7i2.6571.

iPrice. 2020. Peta E-Commerce Indonesia [Internet]. [diakses pada 2021 Maret 26]. Tersedia pada : Daftar 50 Website \& Aplikasi E-Commerce di Indonesia 2019 (iprice.co.id) 
Kim WC, Mauborgne R. 2005. Blue Ocean Strategy. Boston (US): Harvard Business School.

Lackermair G, Kailer D, Kanmaz K. 2013. Importance of Online Product Reviews from a Consumer's Perspective. Adv Econ Bus. 1(1):1-5. doi:10.13189/aeb.2013.010101.

Lee EJ, Shin SY. 2014. When do consumers buy online product reviews? Effects of review quality, product type, and reviewer's photo. Comput Human Behav. 31(1):356-366. doi:10.1016/j.chb.2013.10.050.

Ling KC, Chai LT, Piew TH. 2010. The Effects of Shopping Orientations, Online Trust and Prior Online Purchase Experience toward Customers' Online Purchase Intention. Int Bus Res. 3(3):63. doi:10.5539/ibr.v3n3p63.

Mulyati Y, Gesitera G. 2020. Pengaruh Online Customer Review terhadap Purchase Intention dengan Trust sebagai Intervening pada Toko Online Bukalapak di Kota Padang. $J$ Maksipreneur Manajemen, Koperasi, dan Entrep. 9(2):173. doi:10.30588/jmp.v9i2.538.

Munte RN, Girsang R, Safitri A. 2020. Munte, R. N., Girsang, R., \& Safitri, A. (2020). Pengaruh Online Consumer Review Dan Rating Terhadap. 8(3), 187-192.Pengaruh Online Consumer Review Dan Rating Terhadap Kepercayaan Dan Minat Marketplace Shopee. 8(3):187-192.

Pakdel B. 2013. The Historical Context of Motivation and Analysis Theories Individual Motivation. Int J Humanit Soc Sci. 3(18):240-247.

Park DH, Lee J, Han I. 2006. Information overload and its consequences in the context of online consumer reviews. PACIS 2006 - 10th Pacific Asia Conf Inf Syst ICT Innov Econ. July:197-209.

PricewaterhouseCoopers. 2020. Prioritas Belanja Konsumen Indonesia Setelah Pandemi [Internet]. [diakses pada 2021 Mei 4]. Tersedia pada : Ini Daftar Belanja Prioritas Konsumen Pasca-Pandemi $\mid$ Databoks (katadata.co.id)

Saidani B, Arifin S. 2012. PENGARUH KUALITAS PRODUK DAN KUALITAS LAYANAN TERHADAP KEPUASAN KONSUMEN DAN MINAT BELI PADA RANCH MARKET. Ecobisma (Jurnal Ekon Bisnis Dan Manajemen). 3(1):1-22. doi:10.36987/ecobi.v7i2.1758.

Schiffman L, Kanuk LL. 2007. Perilaku Konsumen [Edisi Ke-7]. Jakarta(ID): PT. Indeks.

Statista. 2019. Tren Pengguna E-Commerce Terus Tumbuh [Internet]. [diakses pada 2021 Maret 26]. Tersedia pada : Tren Pengguna E-Commerce Terus Tumbuh | Databoks (katadata.co.id)

Vinzi VE, Chin WW, Henseler J, Wang H. 2010. Handbook of Partial Least Square. London (GB): Springer Heidelberg Dordrecht.

Zhu F, Zhang X. 2010. Impact of online consumer reviews on Sales: The moderating role of product and consumer characteristics. $J$ Mark. 74(2):133-148. doi:10.1509/jmkg.74.2.133.

Zhu N, Zhang D, Wang W, Li X, Yang B, Song J, Zhao X, Huang B, Shi W, Lu R, et al. 2020. O R I G I N A L A RT I C L E B R I E F R E P O RT A Novel Coronavirus from Patients with Pneumonia in China, 2019. $N$ Engl $J$ Med. December 2019:1-14. https://www.nejm.org/doi/full/10.1056/NEJMoa2001017?fbclid=IwAR2cXbnO9DpcPyQXM1X6xPrDzCeEQWBYbGNioRiZq66RoA8KAnZjdLFfj4. 